\title{
Determination of Target Point Magnification Rate on Stereotactic Angiography for Radiosurgery
}

\author{
- Technical Note-
}

\author{
Masaaki YAMAMOTO and Christer LINDQUIST \\ Department of Neurosurgery, Karolinska Hospital, Stockholm, Sweden
}

\begin{abstract}
We describe here a new method of calculating the target point magnification rate for radiosurgery by stereotactic angiography using a Leksell frame. As the distance (D) between the $\mathrm{x}$-ray focus and the film plane is constant in each facility, the magnification rate $(M)$ is determined by the equation: $M=$ $\mathrm{D} /[\mathrm{D} / \mathrm{Mp}+\mathrm{t}]$, where $\mathrm{Mp}$ is the magnification rate of the proximal (to the $\mathrm{x}$-ray focus) frame projected on the film plane and $t$ is the distance between the proximal frame plane and the target point. The $t$ value is given by the three-dimensionally determined stereotactic coordinates of the target point. Only the $\mathrm{Mp}$ value on the stereotactic angiogram must be measured. This method is theoretically more correct and has less risk of human error than the conventional, graphically determined method which necessitates measuring both the distal and proximal frame magnification rates. Furthermore, the inherent theoretical error of the conventional method is largest around the frame center, which is frequently selected as the target point for radiosurgical treatment, possibly causing serious error in accurate dose planning.
\end{abstract}

Key words: radiosurgery, gamma unit, Leksell frame, stereotactic angiography, magnification rate

\section{Introduction}

The magnification rate at the target point, determined on a stereotactic angiogram, is one of the most important dose-planning parameters for radiosurgery. ${ }^{1)}$ Nowadays, modern microcomputer technology is widely used for the three-dimensional localization of the target point as well as the magnification rate. ${ }^{2)}$ Nevertheless, the graphical determination method is still important and useful, as it requires no special equipment. It is essential that two individuals make separate determinations to avoid human error. It is also advisable for the determination to be made by different methods; graphical and by microcomputer.

We propose a new method of calculating the magnification rate which is considered theoretically more correct and technically less complicated than the conventional, graphically determined method generally used.

\section{Method}

Figure 1 schematically shows two coordinate frames, proximal and distal to the $\mathrm{x}$-ray focus, projected on the film plane of stereotactic angiography using a modern Leksell stereotactic instrument (Model D or G; Elekta Instrument AB, Stockholm, Sweden). ${ }^{1,2)}$ The magnification rate at the target point located within the frame is a value between the two magnification rates, proximal $(\mathrm{Mp})$ and distal $(\mathrm{Md})$, measured on the film (Fig. 2).

Figure 3 shows that $\mathrm{Mp}$ and $\mathrm{Md}$ can be expressed as

$$
M p=D / d, M d=D /[d+18],{ }^{1)}
$$

Received September 9, 1992; Accepted November 2, 1992

Author's present address: M. Yamamoto, M.D., Department of Neurosurgery, Tokyo Women's Medical College Dai-ni Hospital, Tokyo, Japan. 


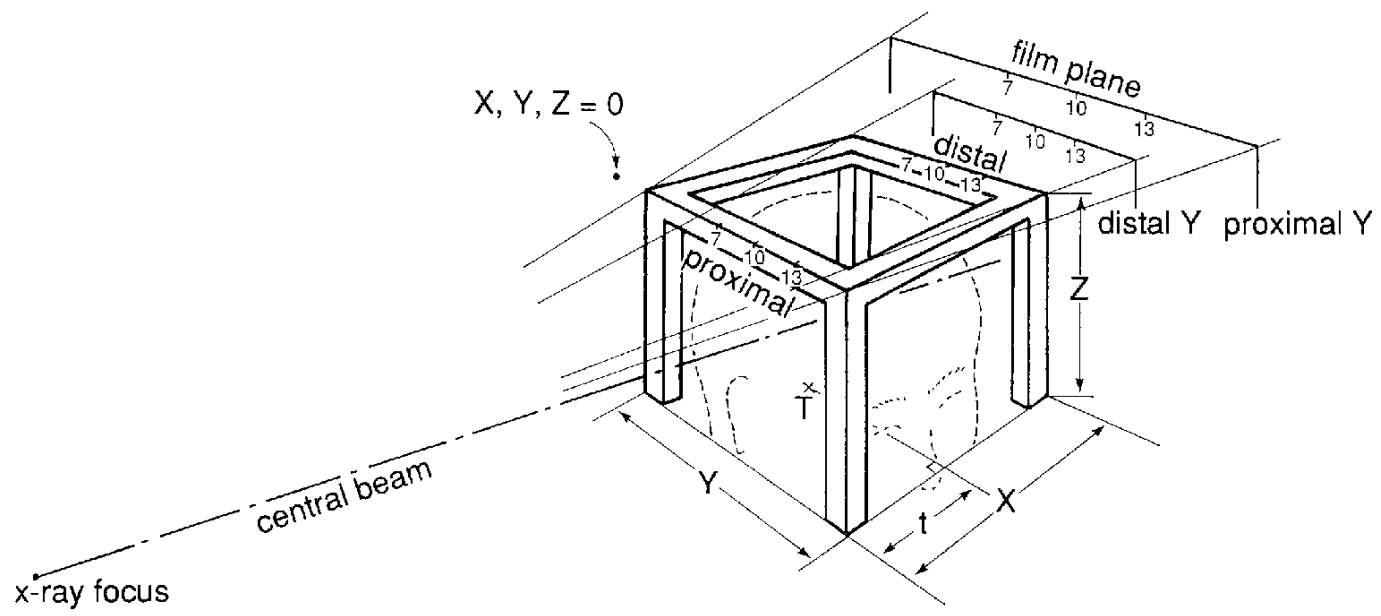

Fig. 1 Schematic drawing, showing projection of the coordinate system on the film plane. $\mathrm{T}$ : target point, $\mathrm{t}$ : distance between the proximal frame plane and the target point, $\mathrm{X}$ : left-right coordinate, $\mathrm{Y}$ : anterior-posterior coordinate, Z: superior-inferior coordinate.

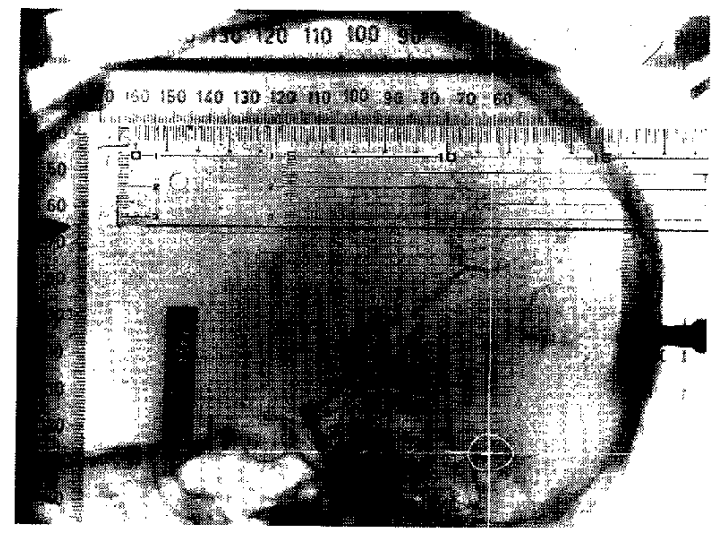

Fig. 2 Lateral projection of a stereotactic angiogram, showing the magnification rate of the distal coordinate (Y) scale.

which can be converted to

$$
\begin{aligned}
& \mathrm{D}=18 \times \mathrm{Mp} \times \mathrm{Md} /[\mathrm{Mp}-\mathrm{Md}], \\
& \mathrm{d}=18 \times \mathrm{Md} /[\mathrm{Mp}-\mathrm{Md}],
\end{aligned}
$$

where $\mathrm{D}$ and $\mathrm{d}$ are the distances between the $\mathrm{x}$-ray focus and the film plane and proximal frame plane, respectively. The distance between proximal and distal frames is $18 \mathrm{~cm}$ in this system. ${ }^{2)}$ In the same way, the magnification rate (M) at the target point is expressed as

$$
\mathrm{M}=\mathrm{D} /[\mathrm{d}+\mathrm{t}] \text {, }
$$

where $t$ is the distance between the proximal frame plane and the target point. Therefore,

$$
\begin{aligned}
\mathrm{M}= & 18 \times \mathrm{Mp} \times \mathrm{Md} /\{18 \times \mathrm{Md}+[\mathrm{Mp}-\mathrm{Md}] \\
& \times \mathrm{t}\},
\end{aligned}
$$

which can be applied whenever the $D$ value is variable. In most facilities, however, D has a constant value $(100 \mathrm{~cm}$ in the Karolinska Hospital, for example). Thus, this function can be also expressed as

$$
\mathrm{M}=\mathrm{D} /[\mathrm{D} / \mathrm{Mp}+\mathrm{t}],
$$

where $t$ is given as [real $X(\mathrm{~cm})-1]$ in the lateral and $[19$ - real Y $(\mathrm{cm})]$ in the frontal projection according to the true stereotactic coordinates of the target point as determined graphically or with a computer; the three-dimensional location of the target point is expressed as real [X, $\mathrm{Y}$, and $\mathrm{Z}$ values] which correspond to left-right, anterior-posterior, and superiorinferior coordinate scales, respectively.

\section{Results}

To compare the magnification rate calculated by this method with the real magnification rate, an example with the distance between the x-ray focus and the frame center of $75 \mathrm{~cm}$ is discussed. This situation is frequently encountered in clinical practice. As the D value is fixed at $100 \mathrm{~cm}$ in the Karolinska Hospital and the $\mathrm{Mp}$ value is $1.515(\mathrm{Mp}=100 / \mathrm{d}=100 / 66)$, the $t$ value-dependent magnification rate can be calculated by the equation:

$$
M=100 /[100 / 1.515+t] \text {. }
$$




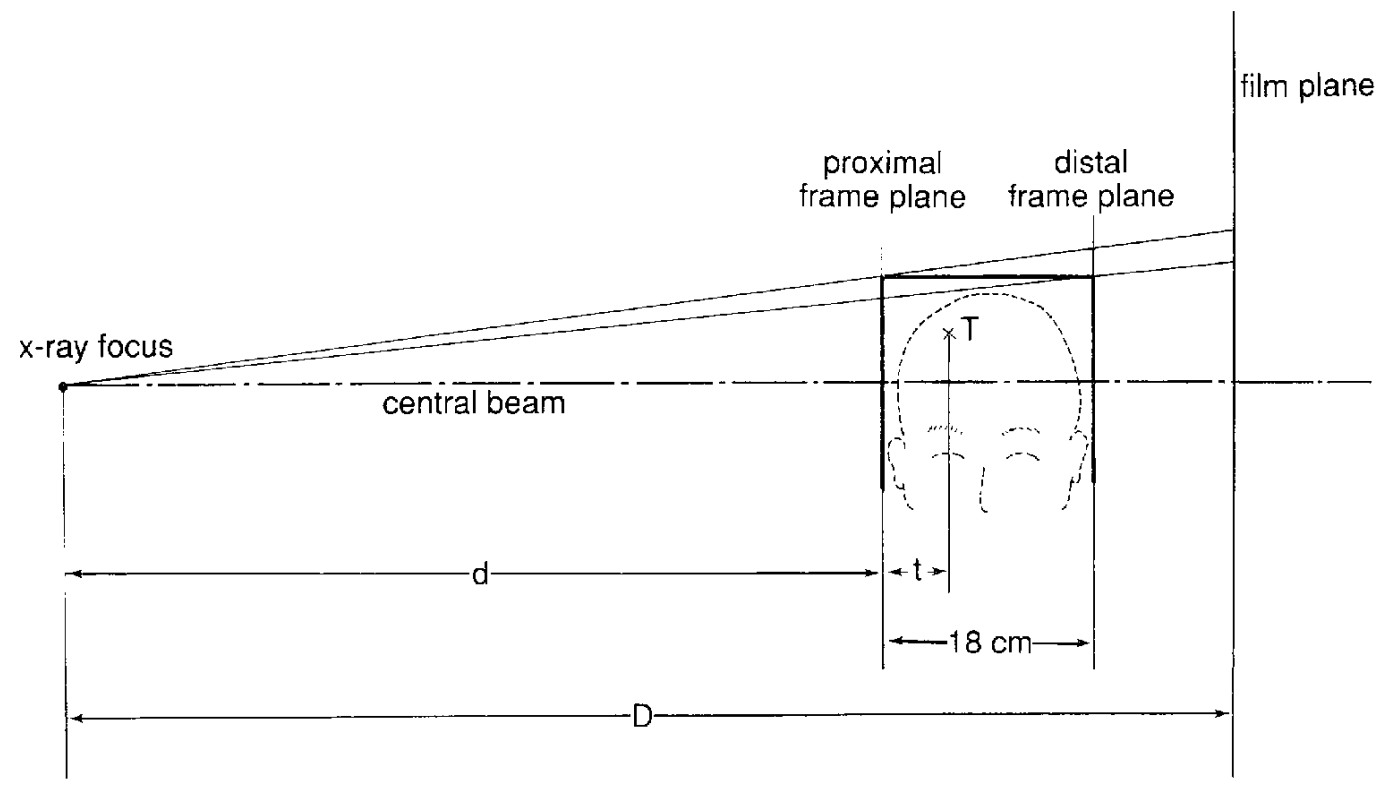

Fig. 3 Schematic drawing, depicting stereotactic angiography. D: distance between the $x$-ray focus and the film plane, $d$; distance between the $x$-ray focus and the proximal frame plane.

Table 1 Comparison of magnification rates calculated by the conventional and our methods with the real rate

\begin{tabular}{|c|c|c|c|}
\hline \multirow{2}{*}{$\begin{array}{l}\text { Distance between } \\
\text { the proximal frame } \\
\text { plane and the } \\
\text { target point }(\mathrm{cm})\end{array}$} & \multirow{2}{*}{$\begin{array}{l}\text { Real } \\
\text { magnifica- } \\
\text { tion } \\
\text { rate }\end{array}$} & \multicolumn{2}{|c|}{$\begin{array}{l}\text { Calculated magnification rate } \\
\text { (difference from real rate) }\end{array}$} \\
\hline & & $\begin{array}{l}\text { Present } \\
\text { method* }\end{array}$ & $\begin{array}{l}\text { Conventional } \\
\text { method }^{* *}\end{array}$ \\
\hline 0 & $1.515^{+}$ & & \\
\hline \multicolumn{4}{|l|}{1} \\
\hline \multicolumn{4}{|l|}{2} \\
\hline \multicolumn{4}{|l|}{3} \\
\hline 4 & 1.429 & $1.428(0.001)$ & $1.443(0.014)$ \\
\hline 5 & 1.408 & $1.408(0.000)$ & $1.425(0.017)$ \\
\hline 6 & 1.389 & $1.389(0.000)$ & $1.407(0.018)$ \\
\hline 7 & 1.370 & $1.370(0.000)$ & $1.389(0.019)$ \\
\hline 8 & 1.351 & $1.351(0.000)$ & $1.371(0.020)$ \\
\hline 9 (frame center) & 1.333 & $1.333(0.000)$ & $1.353(0.020)$ \\
\hline 10 & 1.316 & $1.316(0.000)$ & $1.334(0.018)$ \\
\hline 11 & 1.299 & $1.299(0.000)$ & $1.316(0.017)$ \\
\hline 12 & 1.282 & $1.282(0.000)$ & $1.298(0.016)$ \\
\hline 13 & 1.266 & $1.266(0.000)$ & $1.280(0.014)$ \\
\hline 14 & 1.250 & $1.250(0.000)$ & $1.262(0.012)$ \\
\hline \multicolumn{4}{|l|}{15} \\
\hline \multicolumn{4}{|l|}{16} \\
\hline \multicolumn{4}{|l|}{17} \\
\hline 18 & $1.190^{++}$ & & \\
\hline
\end{tabular}

The frame center is located $75 \mathrm{~cm}$ from the x-ray focus. ${ }^{*} \mathrm{M}=100 /[100 / 1.515+\mathrm{t}],{ }^{* *} \mathrm{M}=1.515-$ [1.515-1.190] $\times \mathrm{t} / 18$, where $M$ : calculated magnification rate, $t$ : distance between the proximal frame plane and the target point. ${ }^{+}$Magnification rate of the proximal frame $(\mathrm{Mp}),{ }^{++}$magnification rate of the distal frame (Md).
The calculated magnification rates differ by less than 0.001 from the real rates, as shown in Table 1 , where the corresponding $\mathrm{t}$ value-dependent magnification rates ranging from 1 to 3 and from 15 to 17 have been omitted because they have no practical application.

\section{Discussion}

The magnification rate at the target point has conventionally been determined by the equation:

$$
\mathrm{M}=\mathrm{Mp}-[\mathrm{Mp}-\mathrm{Md}] \times \mathrm{t} / 18 .
$$

However, the relationship between $M$ and $t$ values is hyperbolic rather than linear, as discussed above, so the conventional calculation method is theoretically incorrect. Furthermore, differences between conventionally determined and real magnification rates are maximal around the frame center which is frequently selected as the target point for gamma unit treatment (Table 1). In contrast, the calculation method described here is not only theoretically correct but also simple; all that is required is measurement of the $\mathrm{Mp}$ value on the stereotactic angiogram because the $D$ value is a constant distance in each facility. The conventional method requires measurement of both $\mathrm{Mp}$ and $\mathrm{Md}$ values, increasing the risk of human error. Although the difference, 0.02 , between the conventionally calculated and real rates is relatively small, this inherent theoretical error can be augmented by 
human error. When treating a lesion larger than 3.3 $\mathrm{cm}$ in diameter, a difference of 0.3 or more can result in an underestimate as significant as $1 \mathrm{~mm}$ in comparison with the real size. Because of the theoretical inaccuracy of the conventional method, we suggest that it should not be used for any procedure requiring meticulous dose planning.

\section{Acknowledgment}

The authors would like to thank Bierta E. Barfod, M.D., University of Washington School of Medicine, and Mrs. Nina Loughlin, secretary of the department, for her assistance in the preparation of this manuscript.

This study was supported by scholarships from the Royal Swedish Academy of Sciences, the Japanese
Society for the Promotion of Science, the Japan Private School Promotion Foundation, and the Dr. Itoe Okamoto International Exchange Fund.

\section{References}

1) Leksell L: Stereotaxis and Radiosurgery. Springfield, Ill., CC Thomas, 1971, pp 61-63

2) Lunsford LD, Leksell D: The Leksell system, in Lunsford LD (ed): Modern Stereotactic Neurosurgery. Boston, Nijhoff, 1988, pp 27-46

Address reprint requests to: M. Yamamoto, M.D., Department of Neurosurgery, Tokyo Women's Medical College Dai-ni Hospital, 2-1-10 Nishiogu, Arakawa-ku, Tokyo 116, Japan. 